Received: 2 June 2017

Accepted: 21 November 2017

Published online: 12 December 2017

\section{OPEN The Sam-Sam interaction between Ship2 and the EphA2 receptor: design and analysis of peptide inhibitors}

Flavia Anna Mercurio ${ }^{1}$, Concetta Di Natale ${ }^{2}$, Luciano Pirone ${ }^{1}$, Roberta lannitti ${ }^{1}$, Daniela Marasco $^{1,2}$, Emilia Maria Pedone ${ }^{1}$, Rosanna Palumbo ${ }^{1}$ \& Marilisa Leone ${ }^{1}$

The lipid phosphatase Ship2 represents a drug discovery target for the treatment of different diseases, including cancer. Its C-terminal sterile alpha motif domain (Ship2-Sam) associates with the Sam domain from the EphA2 receptor (EphA2-Sam). This interaction is expected to mainly induce pro-oncogenic effects in cells therefore, inhibition of the Ship2-Sam/EphA2-Sam complex may represent an innovative route to discover anti-cancer therapeutics. In the present work, we designed and analyzed several peptide sequences encompassing the interaction interface of EphA2-Sam for Ship2-Sam. Peptide conformational analyses and interaction assays with Ship2-Sam conducted through diverse techniques (CD, NMR, SPR and MST), identified a positively charged penta-amino acid native motif in EphA2-Sam, that once repeated three times in tandem, binds Ship2-Sam. NMR experiments show that the peptide targets the negatively charged binding site of Ship2-Sam for EphA2-Sam. Preliminary in vitro cell-based assays indicate that -at $50 \mu \mathrm{M}$ concentration- it induces necrosis of PC-3 prostate cancer cells with more cytotoxic effect on cancer cells than on normal dermal fibroblasts. This work represents a pioneering study that opens further opportunities for the development of inhibitors of the Ship2-Sam/EphA2-Sam complex for therapeutic applications.

Several signaling proteins are engaged to the plasma membrane by the lipid second messenger PIP3 (phosphatidylinositol 3,4,5-triphosphate) whose intracellular levels are regulated by phosphoinositide phosphatases. Among them, Ship2 (phosphatidylinositol 3,4,5-triphosphate 5-phosphatase 2) catalyses the dephosphorylation of PIP3 in position 5 to generate phosphatidylinositol $(3,4) \mathrm{P} 2$ and thus, downregulates different processes that are activated by PI3K (Phosphatidyl-Inositol 3 Kinase) ${ }^{1,2}$. In addition to this enzymatic activity, a prominent feature of Ship2 is the presence within its primary sequence of several regions able to mediate protein-protein interactions. In details, Ship2 includes from the $\mathrm{N}$ - to the C-termini a SH2 (Src homology 2) domain, followed by the catalytic 5-phosphatase domain, -NPXY- motifs, that generally recognize phosphotyrosine binding (PTB) domains, a proline-rich domain (PRD) with consensus sequences for SH3 modules and a sterile alpha-motif (Sam) domain ${ }^{3}$.

Ship2 interacts with several other proteins and acts in different processes like receptor internalization, cell spreading and adhesion, actin cytoskeletal reorganization ${ }^{4}$.

Ship2 is a well known target in drug discovery for type 2 diabetes as it modulates insulin sensitivity and obesity $^{5}$. Nevertheless, Ship2 has been linked to other diseases such as neurodegenerative pathologies, atherosclerosis, as well as cancer ${ }^{4}$. The role of Ship2 in cancer needs to be further elucidated and is controversial. Ship2 is over-expressed in colorectal cancer where it indicates poor survival ${ }^{6}$. Ship 2 inhibition and consequent Akt activation in gastric cancer cells contribute to improved tumorigenesis and proliferation ${ }^{7}$. Interestingly, Ship2 modulates EGFR (Epidermal Growth Factor Receptor) signaling: down-regulation of Ship2 in breast cancer cell lines improves EGFR internalization and degradation and arrests cell proliferation ${ }^{8}$.

Ship2 is also an inhibitor of EphA2 receptor endocytosis ${ }^{9}$; EphA2 is a tyrosine kinase receptor that plays a complex role in cancer and is a known target in anticancer drug discovery ${ }^{10}$.

${ }^{1}$ Institute of Biostructures and Bioimaging (IBB), CNR, via Mezzocannone 16, 80134, Naples, Italy. ${ }^{2}$ Department of Pharmacy, Research Centre on Bioactive Peptides (CIRPeB), University of Naples "Federico II", Via Mezzocannone 16, 80134, Naples, Italy. Correspondence and requests for materials should be addressed to M.L. (email: marilisa. leone@cnr.it) 

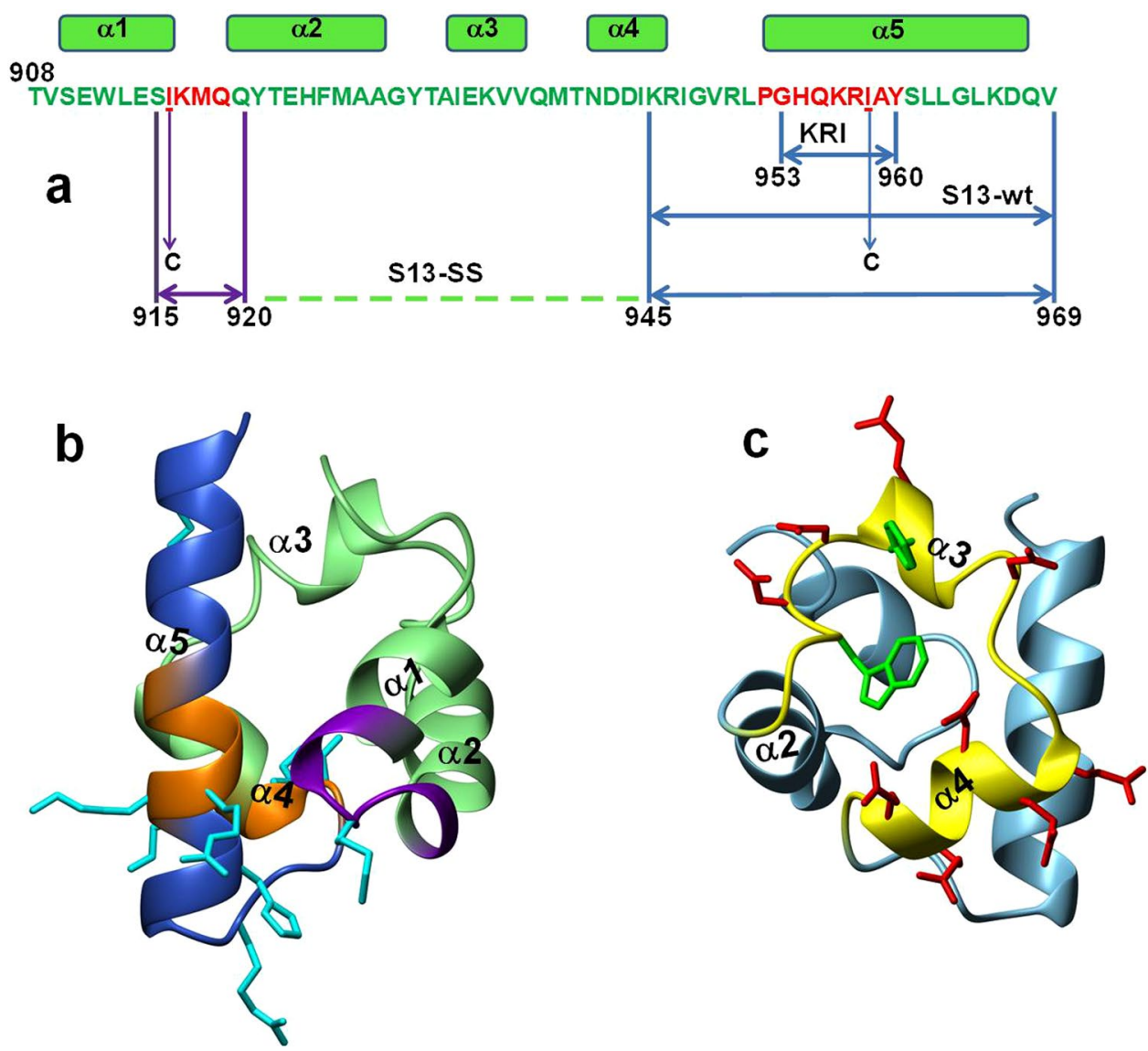

Figure 1. (a) Amino acid sequence of EphA2-Sam (UniprotKB entry P29317 EPHA2_HUMAN) with secondary structure elements indicated on top (from first conformer in pdb entry 2E8N by Goroncy et al., 2007 Structural Genomics/Proteomics Initiative). Residues in the $\alpha 1 \alpha 2$ loop and in the $\alpha 5$ helix belong to the EH region and are colored red. The analyzed peptide segments are delineated by arrows. (b) NMR solution structure of EphA2-Sam (first conformer, pdb entry 2E8N) in a ribbon representation: regions encompassing the S13-wt peptide are colored blue with the "KRI" and "KRIAY" sequences highlighted in orange; the additional fragment contributing to the S13-SS peptide is colored violet. The side chains of positively charged residues are shown in cyan. (c) NMR solution structure of Ship2-Sam (pdb entry 2K4P structure n. $1^{11}$ ). The ML interface is colored yellow and side chains of acidic and aromatic amino acids are reported in red and green respectively.

To achieve modulation of receptor endocytosis, Ship2 needs to associate with EphA2 through a heterotypic Sam-Sam domain interaction?.

The 3D structures of the Sam domains of EphA2 (EphA2-Sam) and Ship2 (Ship2-Sam) ${ }^{11}$ consist of a canonical five helix bundle (Fig. 1). EphA2-Sam and Ship2-Sam bind each other with a dissociation constant in the low micromolar range and a 1:1 stoichiometry ${ }^{11,12}$. The two proteins adopt the ML (Mid-Loop)/EH (End-Helix) interaction model characteristic of Sam/Sam associations ${ }^{11,12}$. The Ship2-Sam/EphA2-Sam complex is highly stabilized by electrostatic contacts between the negatively charged central region of Ship2-Sam (ML site) and the positively charged interface of EphA2-Sam, that includes the C-terminal $\alpha 5$ helix and the adjacent loop (EH site) ${ }^{11}$ (Fig. 1). Moreover, the Sam-Sam complex is highly dynamic and able to sample different conformational states ${ }^{13,14}$.

In cancer cells the interaction between Ship2-Sam and EphA2-Sam is expected to produce mainly pro-oncogenic effects, because Ship2 enhances the ligand-independent pro-migratory function of EphA2 and decreases its ligand-dependent tumor suppressor roles ${ }^{12}$. These findings let speculate that antagonizing the heterotypic Ship2-Sam/EphA2-Sam interaction, by lowering EphA2 pro-oncogenic signaling, may constitute a novel approach for anticancer therapeutics.

With this in mind, we focused on peptide fragments from the EH interface of EphA2-Sam and investigated their conformational properties by means of CD and NMR experiments. Our work highlights that in aqueous solution these fragments do not preserve a native-like fold and are unable to relevantly bind Ship2-Sam in SPR (Surface Plasmon Resonance) and NMR (Nuclear Magnetic Resonance) interaction assays. Nevertheless, these studies led to the identification of a positively charged penta-amino acid motif that, when repeated three times in tandem, binds the ML interface of Ship2-Sam with a dissociation constant in the high micromolar range.

Preliminary in vitro cell based assays demonstrate that the peptide is more cytotoxic to prostate cancer cells (PC-3) than to normal human dermal fibroblasts (NHDF). 


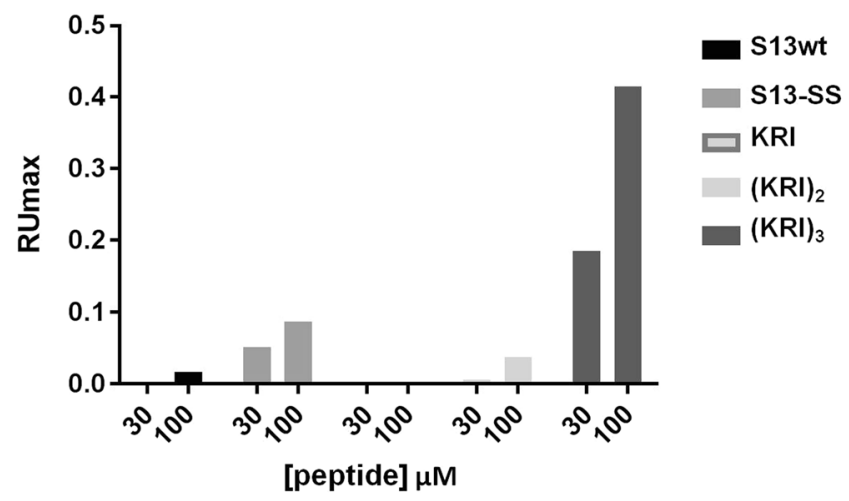

Figure 2. SPR experiments to analyze binding of different peptides to immobilized Ship2-Sam. $\mathrm{RU}_{\max }$ values derive from sensorgrams recorded at two different concentrations (30 and $100 \mu \mathrm{M})$ and signals are normalized for the molecular weight of each peptide.

Our work sheds further light on possible routes to target Sam-Sam interactions mediated by EphA2 and opens a window of opportunities for the design of novel compounds with different therapeutic applications.

\section{Results and Discussion}

Peptide Design. To identify peptide ligands of Ship2-Sam, we analyzed isolated EphA2-Sam regions in or close to the EH interface ${ }^{11}$ (Fig. 1). Thus, the linear S13-wt peptide, corresponding to the 945-969 fragment from EphA2-Sam and, including the C-terminal $\alpha 5$ helix, the $\alpha 4 \alpha 5$ loop and partially the C-terminal end of $\alpha 4$ helix (Fig. 1a,b), was first investigated. The S13-SS peptide was next conceived to better mimic the discontinuous epitope characterizing the EH interface (Fig. 1a). S13-SS includes, in addition to identical S13-wt regions, an EphA2-Sam portion covering mostly the $\alpha 1 \alpha 2$ loop (a.a. 915-920). Moreover, two Isoleucine residues (i.e., Ile916 and Ile958) in the native sequence were mutated to cysteines to allow disulphide linkage of the two segments (915-920 and 945-969) (Fig. 1a,b and Supplemental Table S1).

Since the ML Interface in Ship2-Sam is negatively charged and also contains both a tryptophan and a phenylalanine $^{11}$ (Fig. 1c) we chose to analyze alone the short peptide motif -GHQKRIAY- (hereof named "KRI" peptide, Table S1), that is present at the N-terminal side of $\alpha 5$ helix in EphA2-Sam (Fig. 1a,b). It has been speculated that an intermolecular H-bond involving the backbone amide proton of the Gly residue within the "KRI" peptide sequence, may be crucial for the association between Sam domains ${ }^{15,16}$. Interestingly, the KRI peptide includes both aromatic residues and a stretch of positively charged amino acids which could all interact with the ML interface of Ship2-Sam (Fig. 1c). To maximize potential electrostatic and aromatic interactions with Ship2-Sam, two additional peptides containing the -KRIAY- penta-amino acid motif, repeated two $\left(=(\mathrm{KRI})_{2}\right.$ peptide $)$ and three $\left(=(\mathrm{KRI})_{3}\right.$ peptide) times in tandem were studied as well (Fig. 1a and Supplemental Table S1).

Conformational analysis by CD. Peptide conformational studies were first performed in solution by far-UV CD spectroscopy. CD spectra in aqueous buffer clearly indicate for all peptides a prevalent random coil content for the minimum at $\sim 200 \mathrm{~nm}$ (Supplemental Fig. S1). However, S13-wt and (KRI) ${ }_{3}$ show a certain propensity to assume an $\alpha$-helical conformation as indicated by TFE (2,2,2-trifluoroethanol) titration (Supplemental Fig. S2).

Structural insights by NMR spectroscopy. Additional conformational studies were carried out by NMR spectroscopy. In aqueous solution all peptides appear unstructured in agreement with CD data. Almost complete proton resonance assignments in PBS were obtained for S13-wt (Supplemental Table S2). However, S13-wt and $(\mathrm{KRI})_{3}$ could be better studied in presence of TFE (2,2,2-trifluoroethanol) (Supplemental Figs S3 and S4, Tables S3, S4 and S5). TFE can reveal the intrinsic tendency of an amino-acid sequence to assume a specific secondary structure that may characterize its conformation when interacting with membranes or different peptides/ proteins $s^{17,18}$. Our recent work on several fragments from different Sam domains (Ship $2^{19}$ and the adaptor protein $\operatorname{Odin}^{20}$ ) further shows, in agreement with earliest studies ${ }^{21}$, that native-like helices are well reproduced in solution containing TFE. However, propagation of helical content to the more disordered protein regions may occur at high TFE concentration ${ }^{20}$.

The comparison of Ho chemical shifts deviations from random coil values in PBS and in TFE solution clearly indicates for S13-wt an increase in helical content, with the percentage of helical population, estimated by chemical shifts, raising from $10 \%$ in PBS to $29 \%$ in presence of TFE ${ }^{22}(60 \% \mathrm{v} / \mathrm{v})$ (Supplemental Fig. S3a). NMR studies in TFE reveal a completely native-like fold for the S13-wt peptide (Supplemental Fig. S3b,c and Table S4).

Similarly, structure calculations performed for the $(\mathrm{KRI})_{3}$ peptide in presence of $50 \%$ TFE indicate the presence of an $\alpha$-helix extending through the whole peptide sequence (Supplemental Fig. S4 and Table S5).

Binding studies with EphA2-Sam. SPR and MST experiments. In order to investigate the interaction with Ship2-Sam, all peptides were analysed by SPR experiments (Figs 2, 3 and S5). 


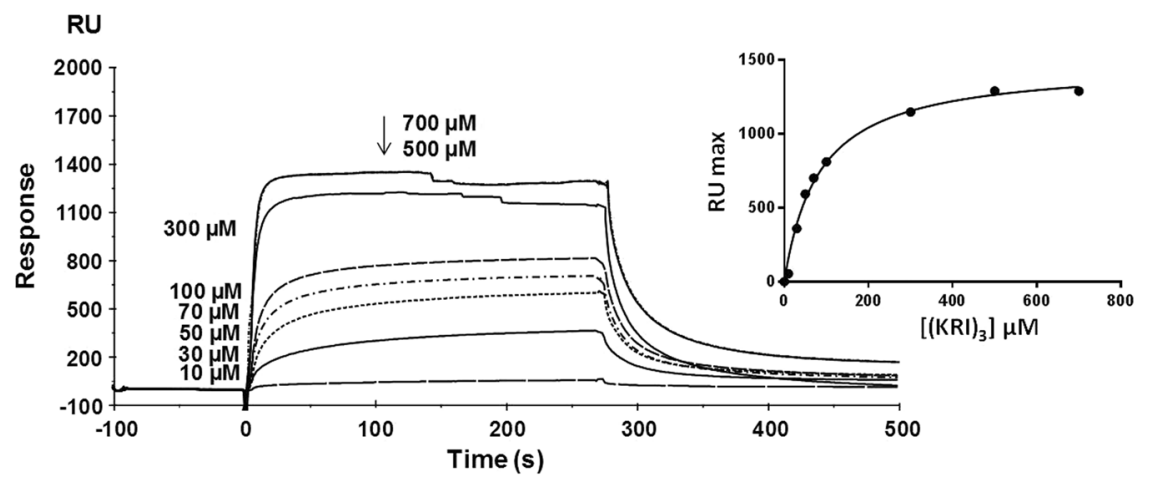

Figure 3. Interaction between $(\mathrm{KRI})_{3}$ and Ship2-Sam monitored by SPR experiments. Sensorgrams were recorded at increasing peptide concentrations and Ship2-Sam was immobilized on the microchip surface. The plot of $\mathrm{RU}_{\max }$ values as function of peptide $(\mathrm{KRI})_{3}$ concentration is shown in the inset.

\begin{tabular}{|l|l|l|l|l|}
\hline & \multicolumn{2}{|l|}{ SPR kinetic } & SPR binding isotherm \\
\hline \multirow{2}{*}{$(\mathrm{KRI})_{3}$} & $\mathrm{k}_{\text {on }}\left(\mathrm{M}^{-1} \mathrm{~s}^{-1}\right)$ & $\begin{array}{l}\mathrm{k}_{\text {off }} \\
\left(\mathrm{s}^{-1} \times 10^{-3}\right)\end{array}$ & $\mathrm{K}_{\mathrm{D}}(\mu \mathrm{M})$ & $\mathrm{K}_{\mathrm{D}}(\mu \mathrm{M})$ \\
\cline { 2 - 5 } & 1100 & 0.110 & 100 & 83 \\
\hline
\end{tabular}

Table 1. Dissociation constants measured in SPR experiments for binding of (KRI) $)_{3}$ to Ship2-Sam.

Histograms of Response Unit (RUmax) values, evaluated at 30 and $100 \mu \mathrm{M}$ concentrations, show that the KRI and $(\mathrm{KRI})_{2}$ peptides are not able to bind Ship2-Sam while $(\mathrm{KRI})_{3}$ and S13-SS generate significant dose-response signal variations (Fig. 2). SPR sensorgrams recorded for S13-SS in a more wide concentration range, indicate that this peptide does not reach saturation (Supplemental Fig. S5b). Sensorgrams of the (KRI) $)_{3}$ peptide, recorded at concentrations of 500 and $700 \mu \mathrm{M}$, appear quite noisy suggesting partial insolubility at the Ship2-Sam interface (Fig. 3). However, (KRI) ${ }_{3}$ curves were fitted according to a single binding site model with 1:1 stoichiometry and provided a $\mathrm{K}_{\mathrm{D}}$ value of $100 \mu \mathrm{M}$, that is in agreement with the one measured by the binding isotherm $\mathrm{K}_{\mathrm{D}}=83 \pm 8 \mu \mathrm{M}$ (Table 1 and Fig. 3 ).

The interaction between the (KRI) ${ }_{3}$ peptide and Ship2-Sam was further investigated by MST (Microscale Thermophoresis) experiments (Supplemental Fig. S6) ${ }^{23}$. MST studies clearly show a protein/peptide interaction but, they do not allow an accurate $\mathrm{K}_{\mathrm{D}}$ measurement due to precipitate formation at the highest $(\mathrm{KRI})_{3}$ peptide concentrations (Supplemental Fig. S6).

NMR and CD assays. To further analyze the interaction between Ship2-Sam and each peptide, an NMR-based screening was conducted by means of chemical shift perturbation experiments with HSQC spectra ${ }^{24}$ and ${ }^{15} \mathrm{~N}$ labeled Ship2-Sam (Figs 4 and S7). These experiments appear in perfect agreement with SPR data and show more significant chemical shifts variations in the spectrum of Ship2-Sam only upon addition of the (KRI) ${ }_{3}$ peptide (Fig. 4). Moreover, as already observed in MST assays, at the highest peptide concentrations (values $>300 \mu \mathrm{M}$ ) precipitation occurs with loss of protein signal (Fig. 4a,b) and this avoids reaching saturating conditions and achieving accurate $K_{D}$ evaluation. Nevertheless, we evaluated CSP (Chemical Shifts Perturbations) induced in the protein spectrum by the peptide and mapped them on the 3D solution structure of Ship2-Sam (Fig. 4c,d). Interestingly, most of the changes affects the highly negatively charged ML region of Ship2-Sam and the external close regions (such as the C-terminal side of $\alpha 5$ helix), which may undergo "indirect" conformational movements. Indeed the pattern of variations closely resembles the ones observed for the interaction between Ship2-Sam and EphA2-Sam ${ }^{11}$ (Fig. 4d).

To further demonstrate that EphA2-Sam and the $(\mathrm{KRI})_{3}$ peptide are (completely or partially) targeting the same Ship2-Sam regions, a displacement experiment ${ }^{25,26}$ was conducted (Fig. 5). Upon addition of unlabelled Ship2-Sam to ${ }^{15} \mathrm{~N}$-labeled EphA2-Sam, the $\left[{ }^{1} \mathrm{H},{ }^{15} \mathrm{~N}\right]$ HSQC spectrum undergoes several changes canonical for the Sam-Sam association (Fig. 5a) ${ }^{11}$. By further adding increasing amounts of the (KRI) ${ }_{3}$ peptide, many peaks within the spectrum of the complex restore the characteristic position of the unbound EphA2-Sam form (Fig. 5b,c,d). However, despite the presence of a large excess of $(\mathrm{KRI})_{3}$, displacement of Ship2-Sam is only partial (Fig. 5b). These results are likely due to the weaker binding affinity of Ship2-Sam for the (KRI) $)_{3}$ peptide (Table 1) with respect to EphA2-Sam (the $\mathrm{K}_{\mathrm{D}}$ value for the Ship2-Sam/EphA2-Sam complex is $0.75 \pm 0.12 \mu \mathrm{M}$ in ITC experiments ${ }^{11}$ ). Interestingly, a patch of negatively charged residues is located in proximity of the $\alpha 2$ helix in Ship2-Sam (Supplemental Fig. S8). We cannot exclude that at the highest peptide concentrations, (KRI) ${ }_{3}$ may also target this area, that is adjacent to the ML interface, and this would reduce the exposed polar surface causing precipitation of the peptide/protein complex.

A transferred-NOESY experiment ${ }^{27}$ was conducted and failed to evidence formation of a rigid defined conformation in the (KRI) ${ }_{3}$ peptide upon binding to Ship2-Sam (Supplemental Fig. S9). Since the relatively low 
a

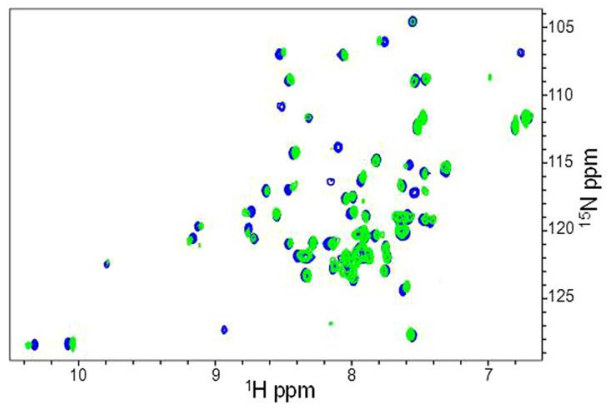

b
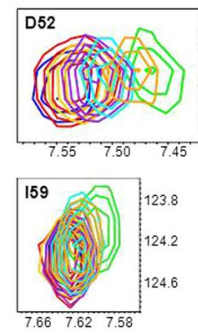
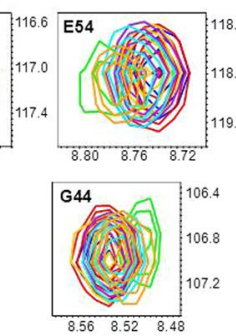

${ }^{1} \mathrm{H}$ ppm

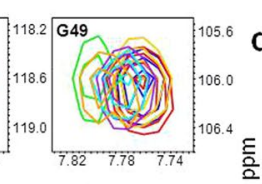

c
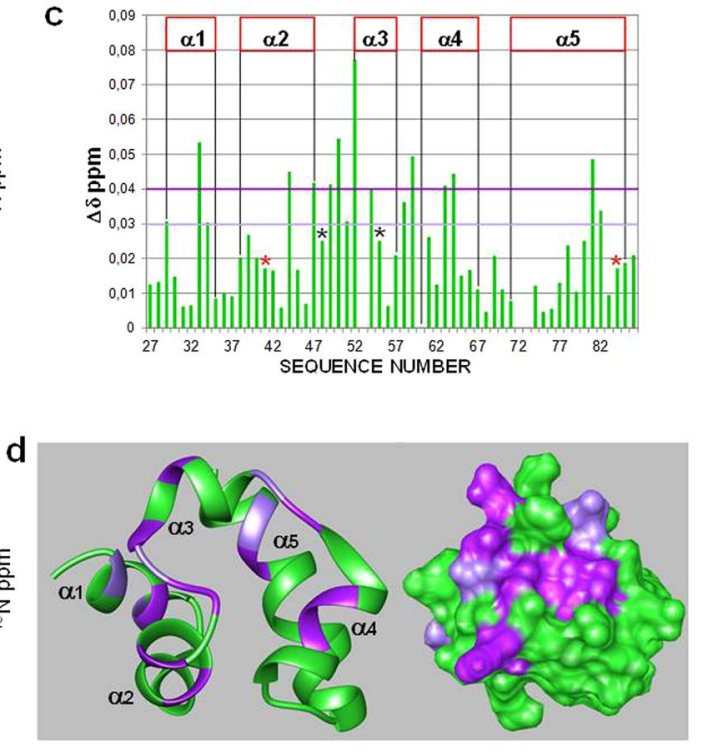

Figure 4. (a) Superposition of $\left[{ }^{1} \mathrm{H}-{ }^{15} \mathrm{~N}\right] \mathrm{HSQC}$ spectra of Ship2-Sam in its apo form $(40 \mu \mathrm{M}$ concentration -blue) and after addition of the $(\mathrm{KRI})_{3}$ peptide ( $2.0 \mathrm{mM}$ concentration -green). (b) A few Ship2-Sam residues, experiencing major chemical shift variations during titration with the $(\mathrm{KRI})_{3}$ peptide, are highlighted. The different panels show the overlays of $\left[{ }^{1} \mathrm{H}-{ }^{15} \mathrm{~N}\right] \mathrm{HSQC}$ spectra of Ship2-Sam alone $(40 \mu \mathrm{M}$ concentration -blue) and in presence of increasing amounts of $(\mathrm{KRI})_{3}(80 \mu \mathrm{M}$-red; $152 \mu \mathrm{M}$-gold; $300 \mu \mathrm{M}$-purple; $586 \mu \mathrm{M}$-cyan; $1.1 \mathrm{mM}$ -orange; $2.0 \mathrm{mM}$-green $)$. (c) Graph reporting normalized chemical shift deviations $\left(\Delta \delta=\left[\left(\Delta \mathrm{H}_{\mathrm{N}}\right)^{2}+(0.17\right.\right.$ $\left.\left.\left.* \Delta^{15} \mathrm{~N}\right)^{2}\right]^{1 / 2}\right)^{55}$ versus residue number. $\Delta \delta$ values were set equal to 0 for P72 as well as L53, T60 whose peaks disappear during titration. $\Delta \delta$ values are ambiguous for Y41 and L84 (red stars) and for N48 and F55 (black stars) due to spectral overlaps. (d) Residues with normalized chemical shifts deviations ( $\Delta \delta$ values) $\geq 0.04 \mathrm{ppm}$ (i.e., L33, G44, H47, G49, W50, D52, E54, I59, D63, L64, T81) or comprised between 0.03 and 0.04 ppm (i.e., M29, R34, D51, D58, L82) are colored in dark and light violet respectively on the 3D solution structure of Ship2-Sam (pdb entry $2 \mathrm{~K} 4 \mathrm{P}$, conformer number 1 ) in its ribbon (left) and surface (right) representations.

molecular weight of Ship2-Sam might have avoided observing peptide folding by NMR upon association with the protein ${ }^{27}, \mathrm{CD}$ spectra were as well recorded for $(\mathrm{KRI})_{3}$ in the presence of different equivalents of Ship2-Sam (Supplemental Fig. S10). The overlay of CD spectra indicates a certain increase of order upon complex formation but, in agreement with NMR data, allows excluding a $(\mathrm{KRI})_{3}$ bound conformation provided with a fully defined secondary structure (Supplemental Fig. S10).

Effects of $(\mathrm{KRI})_{3}$ peptide in cancer cells. After conjugating the peptide $(\mathrm{KRI})_{3}$ to a cell penetrating sequence (i.e., fragment 48-60 from the HIV TAT sequence (Supplemental Table S1) ${ }^{28,29}$ ), its effects in a cellular context were evaluated (Fig. 6). Upon assessing cellular uptake (Fig. 6a), cell viability was first investigated in absence and presence of the FITC (Fluorescein-Isothiocyanate)-TAT-(KRI) 3 peptide in the carcinoma prostate cancer cell line PC-3 (Fig. 6b). PC-3 cells were chosen due to their high endogenous levels of EphA2 $2^{30,31}$ and Ship $2^{32}$. After treatment with the FITC-TAT-(KRI) ${ }_{3}$ peptide $(50 \mu \mathrm{M}$ and $200 \mu \mathrm{M}$ concentrations) a reduction of cell viability of approximately $30 \%$ and $90 \%$ respectively, compared to the untreated cells, was observed (Fig. 6b).

NMR analysis of the FITC-TAT-(KRI) $)_{3}$ peptide clearly indicates that the conformational freedom of the $(\mathrm{KRI})_{3}$ peptide is not influenced by the presence of the FITC-TAT unit (Supplemental Fig. S11). To exclude that the reduction of cell viability could be merely linked to the FITC or the TAT sequence, experiments were conducted with FITC-TAT-Pep1 (Supplemental Table S1 and Fig. S12). We previously described Pep1 as a weak EphA2-Sam ligand with an amino acid sequence encompassing the central regions of the first Sam domain of Odin ${ }^{20}$. At $250 \mu \mathrm{M}$ concentration FITC-TAT-Pep1 induces only a small decrease of PC-3 cells viability (Supplemental Fig. S12) thus indicating that cytotoxicity of FITC-TAT-(KRI) ${ }_{3}$ is specifically linked to the $(\mathrm{KRI})_{3}$ sequence.

Moreover, the activity of FITC-TAT-(KRI) ${ }_{3}$ was also analyzed in Normal Human Dermal Fibroblasts (NHDF). The FITC-TAT-(KRI) $)_{3}$ peptide, at the highest tested concentration (i.e., $200 \mu \mathrm{M}$ ), has less cytotoxic activity in NHDF than in PC-3 cells (Fig. 6b).

The FITC-TAT-(KRI $)_{3}$ peptide induces necrosis of PC-3 cells by damaging plasma membrane and causing LDH (lactate dehydrogenase) leakage (Fig. 6c ${ }^{33}$.

It has recently been pointed out that pro-necrotic peptides may represent a different route to overcome the limits of pro-apoptotic anti-cancer compounds and that their specificity towards cancer cells can be highly increased by fusion to tumor-homing motifs ${ }^{34}$.

To get further insights into the biological function of the (KRI) ${ }_{3}$ peptide, its "KRIAY" motif was searched against a database of bioactive peptides (i.e., the EROP (Endogenous Regulatory OligoPeptide knowledgebase)-Moscow at http://erop.inbi.ras.ru// ${ }^{35}$ but no hits could be retrieved. Nevertheless, a similar search of the 
a

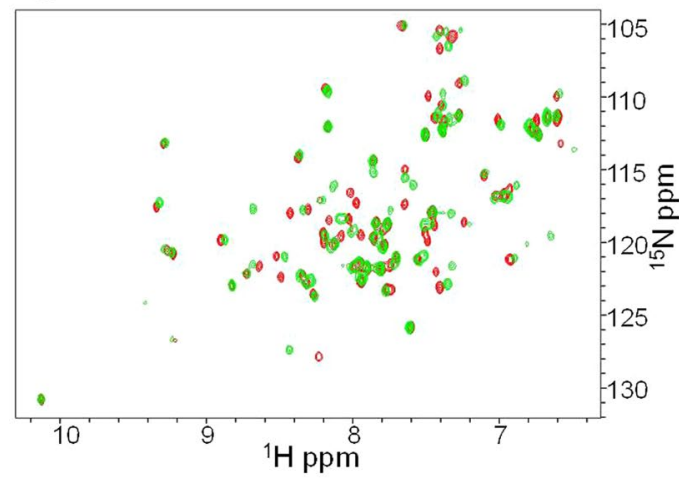

b

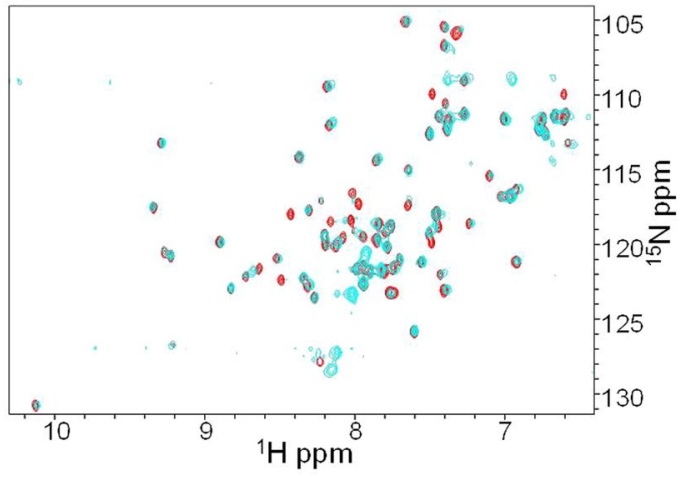

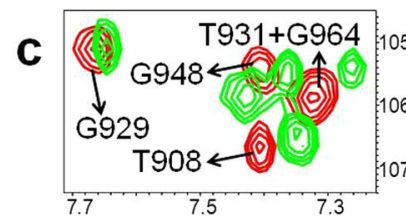

d

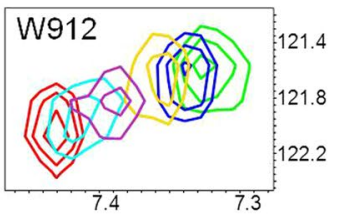

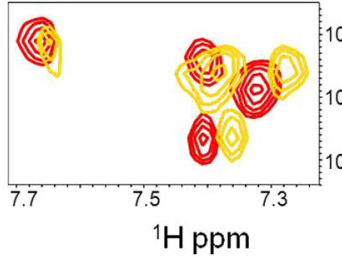
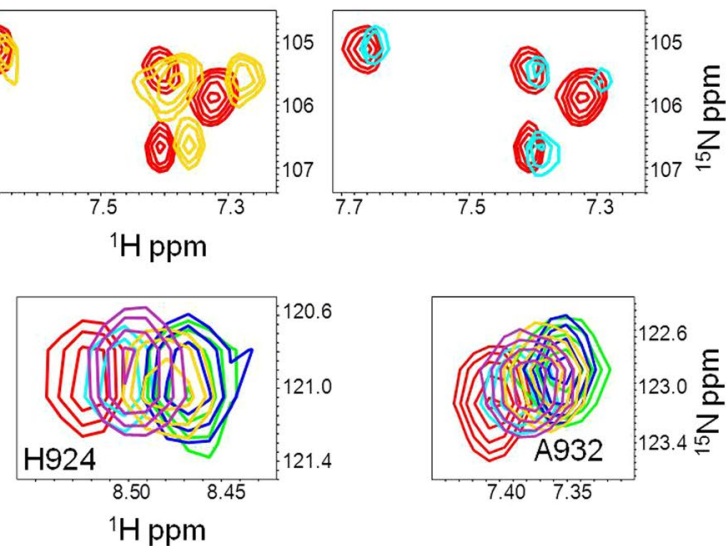

${ }^{1} \mathrm{H} \mathrm{ppm}$

Figure 5. (a,b) Superposition of $\left[{ }^{1} \mathrm{H}_{-}{ }^{15} \mathrm{~N}\right]$ HSQC spectra of ${ }^{15} \mathrm{~N}$ labeled EphA2-Sam $(25 \mu \mathrm{M}$, red), bound to unlabeled Ship2-Sam $\left(80 \mu \mathrm{M}\right.$, green) (a), and after addition of $(\mathrm{KRI})_{3}(7 \mathrm{mM}$ concentration) to the complex (cyan) (b). (c) Expansion of the Gly-Thr region in HSQC spectra of ${ }^{15} \mathrm{~N}$ labeled EphA2-Sam in the free form (red in all panels), in presence of unlabeled Ship2-Sam (green, left panel), and after addition of (KRI) $)_{3}(2.2 \mathrm{mM}$ concentration -gold, middle panel and $7 \mathrm{mM}$ concentration -cyan, right panel). (d) Overlays of $\left[{ }^{1} \mathrm{H}-{ }^{15} \mathrm{~N}\right] \mathrm{HSQC}$ spectra showing results of the displacement experiment for a few residues (red: ${ }^{15} \mathrm{~N}$ EphA2-Sam apo; green: ${ }^{15} \mathrm{~N}$ EphA2-Sam/Ship2-Sam complex; blue: ${ }^{15} \mathrm{~N}$ EphA2-Sam/Ship2-Sam $+(\mathrm{KRI})_{3}$ at $1.1 \mathrm{mM}$ concentration; gold: ${ }^{15} \mathrm{~N}$ EphA2-Sam/Ship2-Sam $+(\mathrm{KRI})_{3}$ at $2.2 \mathrm{mM}$ concentration; purple: ${ }^{15} \mathrm{~N}$ EphA2-Sam/Ship2-Sam $+(\mathrm{KRI})_{3}$ at $4.9 \mathrm{mM}$ concentration; cyan: ${ }^{15} \mathrm{~N}$ EphA2-Sam/Ship2-Sam $+(\mathrm{KRI})_{3}$ at $7 \mathrm{mM}$ concentration).

"KRI" sequence produced several positive results including antimicrobial and antibacterial peptides ${ }^{36,37}$. On the same time, no hits could be retrieved by searching the sequence "KRIAY" against a database of anticancer peptides and proteins (http://crdd.osdd.net/raghava/cancerppd/) whereas the search of the "KRI" sequence produced several results among antibacterial and antimicrobial peptides with anticancer activity. In major details, the "KRI" three amino acid motif is found in the peptide Cecropin P1, that has biological activity against diverse bacteria as well as mammalian leukemias and lymphomas ${ }^{38}$; in the peptide LL-37 $7^{39,40}$, that reduces cell viability in many cancer cell lines including ovarian (OVRCAR-3), breast (MCF-7) and prostate cancer cell lines (LNCaP); finally in the peptide NK-11 that is active against skin cancer ${ }^{41}$.

\section{Conclusions}

Targeting the Ship2-Sam/EphA2-Sam complex with peptide antagonists may represent an alternative approach for the discovery of anticancer therapeutics. Thus, we analyzed isolated fragments of EphA2-Sam encompassing its binding site for Ship2-Sam (EH interface) and the close loop regions. We adopted a multidisciplinary methodology involving conformational analysis by CD and NMR spectroscopies, binding assays by NMR, SPR and MST techniques, in vitro cell-based experiments.

Structural studies point out that isolated EphA2-Sam fragments maintain a relatively poor native-like fold in aqueous buffer and are unable to bind Ship2-Sam with high affinity and specificity. However, careful analysis of obtained results along with inspection of the EphA2-Sam sequence, surrounding its binding interface for Ship2-Sam, led us to identify a "KRIAY" motif, made up of amino acids that could provide important interactions with the negatively charged ML surface. This penta-amino acid motif if repeated three times in $\operatorname{tandem}\left(=(\mathrm{KRI})_{3}\right.$ peptide in Table S1) produces appreciable binding to Ship2-Sam. Preliminary in cell studies show that the (KRI) ${ }_{3}$ peptide is endowed with higher cytotoxicity against PC-3 prostate carcinoma cell line, in which endogenous levels of both EphA2 and Ship2 are elevated, compared to normal fibroblasts. The peptide contains a "KRI" three amino-acid sequence that is common to several antibacterial and antimicrobial peptides provided with anticancer activity ${ }^{38,41}$. Additional cell-based investigations are needed to clarify the mechanism of action of the 
a
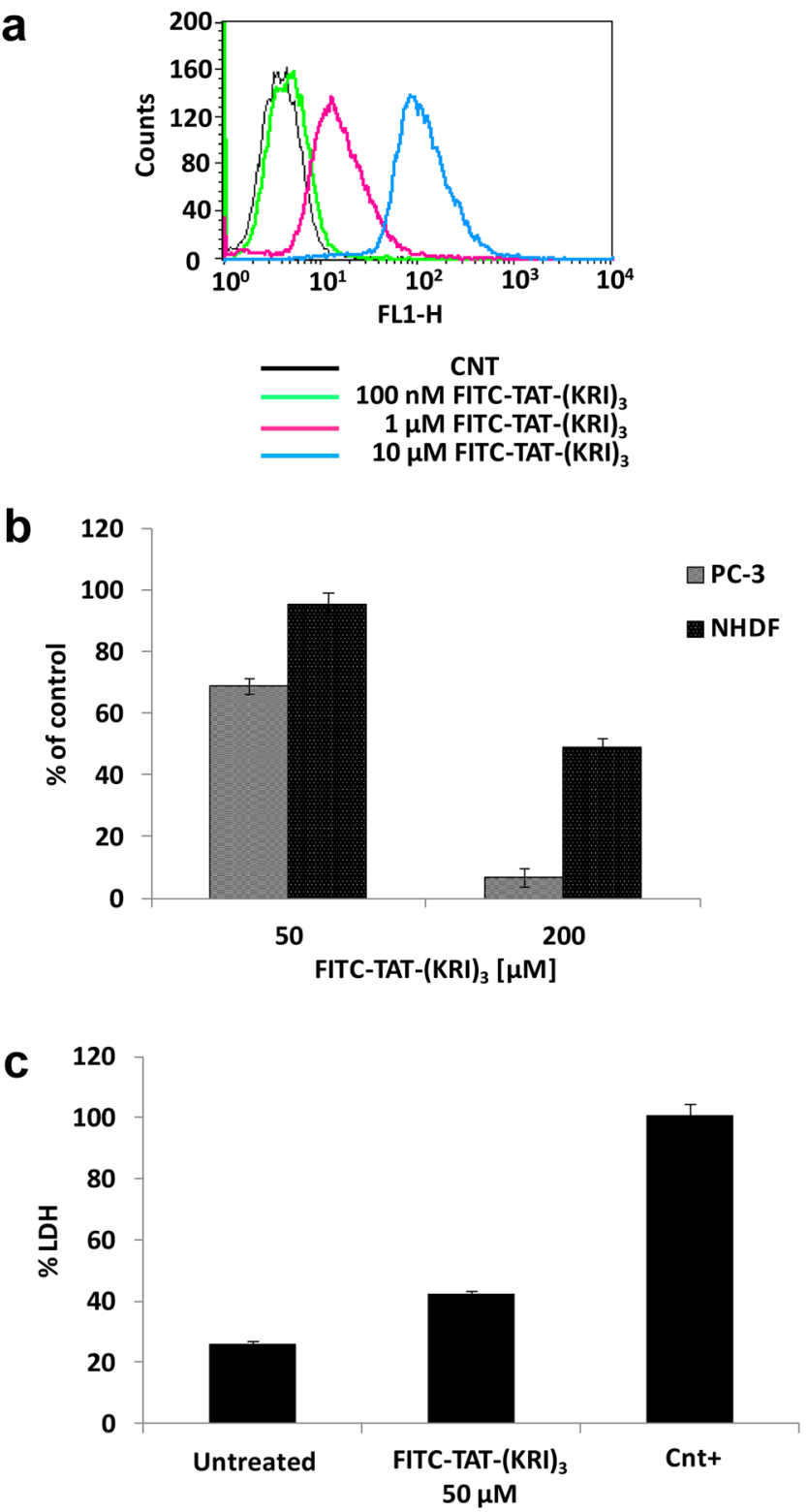

Figure 6. Cellular uptake and in vitro cytotoxicity of FITC-TAT-(KRI) $)_{3}$. (a) Internalization of the peptide was detected by flow cytometric analysis on permeabilized PC-3 cells after incubation with different amounts of FITC-TAT-(KRI) ${ }_{3}$ for 4 hours. Untreated cells were used as negative control (CNT). The histogram was obtained from a single experiment and was representative of three independent measurements. (b) The effect of FITCTAT-(KRI $)_{3}$ on cell viability was assessed on PC-3 and NHDF cells. Cancer and normal cells were incubated with peptide at 50 and $200 \mu \mathrm{M}$ concentrations, after 4 hours the crystal violet assay was performed. Data are expressed as percentage of negative control. (c) The cytotoxic effect of $50 \mu \mathrm{M}$ FITC-TAT-(KRI) ${ }_{3}$ on PC- 3 cells was evaluated by measuring the LDH release in culture medium. PC-3 cells treated with $1 \%$ Triton X-100 were used as positive control ( $\mathrm{Cnt}+$ ). The percentage of released LDH was calculated as indicated in the Materials and Methods. Each value is the mean \pm SD of three independent experiments that were each performed in quadruplicate.

$(\mathrm{KRI})_{3}$ peptide in cancer cells and to establish its correlation to the EphA2/Ship2 signaling. Although the (KRI) 3 peptide shows some cytotoxicity in normal cells we envision that an increase in selectivity towards cancer cells could be achieved through fusion with tumor-homing motifs ${ }^{34}$ or peptide sequences specific for tumor cells over-expressing EphA2 receptor ${ }^{42,43}$.

In conclusion, the $(\mathrm{KRI})_{3}$ peptide represents a "pioneering peptide ligand" of Ship2-Sam, and opens additional opportunities for the rational design of original classes of active peptide antagonists of the Ship2-Sam/ EphA2-Sam complex which could modulate EphA2 receptor endocytosis and degradation, lowering its pro-oncogenic signaling. 


\section{Methods}

Peptides. Peptides were purchased from Proteogenix (Schiltigheim, France) with high purity ( $>95 \%)$, $\mathrm{N}$-terminal acetylation and C-terminal amidation (Supplemental Table S1). For cell-based assays the peptides $\mathrm{Pep}^{20}$ and $(\mathrm{KRI})_{3}$ were conjugated to a modified TAT sequence (GRKKRRQRRRPPQGG) ${ }^{28}$ and to a FITC moiety and were amidated at the C-termini (See Table S1 for details).

NMR experiments. NMR experiments were acquired on a Varian Unity Inova $600 \mathrm{MHz}$ spectrometer equipped with a cold probe. For S13-wt $\left(1.7 \mathrm{mM}\right.$ concentration) a first set of $1 \mathrm{D}\left[{ }^{1} \mathrm{H}\right]$ and $2 \mathrm{D}\left[{ }^{1} \mathrm{H},{ }^{1} \mathrm{H}\right]$ spectra were recorded at $\mathrm{T}=298 \mathrm{~K}$ in $\mathrm{PBS} \mathrm{pH}=7.4$ (composition: $10 \mathrm{mM}$ phosphates, $137 \mathrm{mM} \mathrm{NaCl}$, and $2.7 \mathrm{mM}$ $\mathrm{KCl}$, from Sigma-Aldrich, Milan-Italy), $600 \mu \mathrm{L}$ sample total volume, $10 \%(\mathrm{v} / \mathrm{v}) \mathrm{D}_{2} \mathrm{O}(98 \% \mathrm{D}$, Armar Scientific, Switzerland). Additional NMR experiments were conducted by dissolving the peptide ( $830 \mu \mathrm{M}$ concentration) in $600 \mu \mathrm{L}$ of a mixture 2,2,2-trifluoroethanol-d3 (TFE, 99.5\% isotopic purity, Sigma-Aldrich)/ $\mathrm{H}_{2} \mathrm{O}(60 / 40 \mathrm{v} / \mathrm{v}$ ). The peptides S13-SS, KRI, $(\mathrm{KRI})_{2},(\mathrm{KRI})_{3}$, FITC-TAT-(KRI) ${ }_{3}$ were first dissolved in PBS at $\mathrm{pH}=7.4$ at concentrations equal to $1.2,1.2,1.5,1.0,0.29 \mathrm{mM}$ respectively. NMR spectra were also recorded for $(\mathrm{KRI})_{3}$ at 500 $\mu \mathrm{M}$ concentration in presence of $50 \% \mathrm{v} / \mathrm{v}$ TFE. The set of $2 \mathrm{D}\left[{ }^{1} \mathrm{H},{ }^{1} \mathrm{H}\right]$ experiments, that were recorded and analyzed for each peptide under the different experimental conditions (as indicated above), included: TOCSY (Total Correlation Spectroscopy) ${ }^{44}$, NOESY (Nuclear Overhauser Enhancement Spectroscopy) ${ }^{45}$, and DQFCOSY (Double Quantum-Filtered Correlated Spectroscopy) ${ }^{46}$. The following acquisition parameters were generally implemented for 2D spectra: 16-64 scans, 128-256 FIDs in t1, 1024 or 2048 data points in t2, TOCSY mixing time equal to $70 \mathrm{~ms}$, NOESY mixing times equal to 200 and $300 \mathrm{~ms}$. Excitation Sculpting ${ }^{47}$ was used for water suppression. The process of proton resonance assignments was carried out with the standard Wüthrich protocol ${ }^{48}$. Chemical shifts were referenced to internal TSP (Trimethylsilyl-3-propionic acid sodium salt-D4, 99\% D, Armar Scientific, Switzerland) $(0.0 \mathrm{ppm})$.

Spectra were processed with VNMRJ 1.1D (Varian, Italy) and analyzed with the software NEASY ${ }^{49}$ included in CARA (http://cara.nmr.ch/doku.php/).

The procedure suggested by Kjaergaard and collaborators was used to estimate chemical shift deviations from random coil values for Ho protons (CSD) (http://wwwl.bio.ku.dk/english/research/bms/research/sbinlab/ groups/mak/randomcoil/script//50.

Helical populations were obtained with the equation:

$$
\left[\Delta \delta_{\text {Halpha-average }} /(-0.39)\right] \times 100
$$

where $\left[\left(\mathrm{CSD}=\Delta \delta_{\mathrm{H \alpha}}=\delta_{\mathrm{Hoobserved}}-\delta_{\text {Horandom-coil }}\right)\right]$ was averaged over residues in a helical conformation ${ }^{22}$.

Structure calculations and analysis. The NMR solution structures of $\mathrm{S} 13-\mathrm{wt}$ in $\mathrm{TFE} / \mathrm{H}_{2} \mathrm{O}(60 / 40 \mathrm{v} / \mathrm{v})$ and of $(\mathrm{KRI})_{3}$ in TFE/PBS $(50 / 50 \mathrm{v} / \mathrm{v})$ were calculated using CYANA $2.1^{51}$. Distance constraints were obtained from $2 \mathrm{D}$ $\left[{ }^{1} \mathrm{H},{ }^{1} \mathrm{H}\right]$ NOESY spectra (300 ms mixing time), and angular constraints were generated with the GRIDSEARCH module of CYANA. Structure calculations were initiated from 100 random conformers; the 20 structures provided with the lowest CYANA target functions were additionally validated with the programs MOLMOL ${ }^{52}$ and $\mathrm{iCING}^{53}$. The S13-wt structures were deposited in the PDB Database under accession code: $5 \mathrm{NZ9.}$

NMR interaction studies. To monitor peptide binding to Ship2-Sam chemical shift perturbation studies were conducted by means of $2 \mathrm{D}\left[{ }^{1} \mathrm{H},{ }^{15} \mathrm{~N}\right] \mathrm{HSQC}$ experiments ${ }^{24}$. In detail, $\left[{ }^{1} \mathrm{H},{ }^{15} \mathrm{~N}\right] \mathrm{HSQC}$ spectra were acquired for ${ }^{15} \mathrm{~N}$ labeled Ship2-Sam (concentration $25 \mu \mathrm{M}$ ) in absence and presence of a) S13-wt ( $870 \mu \mathrm{M}$ concentration), b) S13-SS (1.1 mM concentration); c) KRI ( $1 \mathrm{mM}$ concentration), d) (KRI $)_{2}(1 \mathrm{mM}$ concentration), for these binding experiments peptides were all dissolved in protein buffer (i.e., $\mathrm{PBS} \mathrm{pH}=7.4$ ).

Binding of the peptide (KRI) ${ }_{3}$ to Ship2-Sam was investigated by recording several $2 \mathrm{D}\left[{ }^{1} \mathrm{H},{ }^{15} \mathrm{~N}\right] \mathrm{HSQC}$ spectra of ${ }^{15} \mathrm{~N}$ labeled Ship2-Sam at a fixed concentration $(=40 \mu \mathrm{M})$ in absence and presence of increasing amounts of peptide (i.e., 80, 152, 300, 586, 1100, $2000 \mu \mathrm{M}$ ). During NMR titrations the $\mathrm{pH}$ was checked at each point and eventually adjusted to 7.4 with addition of small aliquots of a concentrated $\mathrm{NaOH}$ solution. A NOESY spectrum $\left(300 \mathrm{~ms}\right.$ mixing time) was as well recorded for $(\mathrm{KRI})_{3}$ (concentrations equal to $800 \mu \mathrm{M}$ ) after addition of Ship2-Sam ( $40 \mu \mathrm{M}$ concentration).

Displacement experiment. To assess if $(\mathrm{KRI})_{3}$ could compete with EphA2-Sam for the same binding site on the surface of Ship2-Sam, we performed a displacement experiment through $2 \mathrm{D}\left[{ }^{1} \mathrm{H},{ }^{15} \mathrm{~N}\right]-\mathrm{HSQC}$ spec$\operatorname{tra}^{15,25,26}$. We first recorded a spectrum of ${ }^{15} \mathrm{~N}$ labeled EphA2-Sam in its free form then, unlabeled Ship2-Sam was added to the sample and consequent changes in the HSQC were revealed. Finally, we tried to restore the spectrum of unbound EphA2-Sam by addition of $(\mathrm{KRI})_{3}$ (EphA2-Sam concentration equal to $25 \mu \mathrm{M}$, Ship2-Sam concentration equal to $80 \mu \mathrm{M}$, peptide concentrations equal to $1.1 \mathrm{mM}, 2.2 \mathrm{mM}, 4.9 \mathrm{mM}$, and $7 \mathrm{mM}$ ).

Circular Dichroism. CD spectra were recorded in a $0.1 \mathrm{~cm}$ path-length quartz cuvette on a Jasco J-810 spectropolarimeter (JASCO Corp, Milan, Italy) as already described ${ }^{20,23}$. Spectra derived from the average of three scans, the subtraction of blanks and the conversion of the signal to mean residue ellipticity $\left(\operatorname{deg} \times \mathrm{cm}^{2} \times \mathrm{dmol}^{-1} \times \mathrm{res}^{-1}\right)$. All peptides were analyzed at $100 \mu \mathrm{M}$, in $10 \mathrm{mM}$ phosphate at $\mathrm{pH}=7.2$ and for $(\mathrm{KRI})_{3}$ and S13-wt TFE titrations were carried out as well. CD spectra of $(\mathrm{KRI})_{3}$ were also recorded in presence of Ship2-Sam at different peptide_protein ratios (See Supplemental Material for details).

SPR. SPR experiments were conducted as previously reported ${ }^{23}$. Ship2-Sam domain was efficiently immobilized by employing a solution at a concentration equal to $25 \mu \mathrm{g} / \mathrm{mL}$ in acetate buffer $(10 \mathrm{mM}$ and $\mathrm{pH}=5.0)$, at a 
flow-rate of $5 \mu \mathrm{L} / \mathrm{min}$ and an injection time of $7 \mathrm{~min}$, on a CM5 sensor chip through amine-coupling procedure; the immobilization level was 2065 RU.

SPR assays were conducted with the following parameters: (i) flow: $20 \mu \mathrm{L} / \mathrm{min}$, (ii) contact time: $4.5 \mathrm{~min}$; (iii) running buffer: HBS (HEPES (10 mM), $\mathrm{NaCl}(150 \mathrm{mM})$, EDTA $(3 \mathrm{mM}), \mathrm{pH} 7.4)$.

Reference channel signals were subtracted as blanks and the software BIAevaluation (version 4.1, GE Healthcare) was employed to estimate kinetic and thermodynamic parameters of the complexes. The Graph-Pad Prism software (version 7.00; GraphPad Software, San Diego, California) was used to fit $\mathrm{RU}_{\max }$ for (KRI) ${ }_{3}$ concentrations by nonlinear regression analysis.

MST. A Monolith NT 115 system (Nano Temper Technologies) with 100\% LED and 40\% IR-laser power was used to perform MST experiments. The His-Tag Labeling Kit RED-tris-NTA was implemented to achieve protein labeling. For Ship2-Sam labeling, the protein concentration was adjusted to $100 \mathrm{nM}$ in labeling buffer (Nano Temper Technologies) ${ }^{54}$, while the dye concentration was set to $100 \mathrm{nM}$. Both protein and fluorescent dye solutions were incubated at room temperature in the dark for $30 \mathrm{~min}$. A 16-step serial dilution (1:1) was prepared for $(\mathrm{KRI})_{3}$ (final concentration range $250 \mu \mathrm{M}-7.6 \mathrm{nM}$ ) and premium capillaries were filled with samples. Measurements were conducted at $25^{\circ} \mathrm{C}$ in PBS supplemented with $0.05 \%$ Tween-20. An equation implemented by the software MO-S002 MO Affinity Analysis, provided by the manufacturer, was used for fitting normalized fluorescence values at different $(\mathrm{KRI})_{3}$ concentrations.

Protein expression and purification. Recombinant EphA2-Sam and Ship2-Sam were expressed in E. coli. Protein constructs along with expression and purification methodologies have been reported in our previous publications ${ }^{11,20,23}$. Proteins were either produced in LB (Luria-Bertani) broth or M9 minimal medium supplemented with $1 \mathrm{~g} / \mathrm{L}$ of ${ }^{15} \mathrm{NH}_{4} \mathrm{Cl}$. Bacteria were grown at $37^{\circ} \mathrm{C}$ till a cell optical density $\mathrm{OD}_{600 \mathrm{~nm}}$ equal to 0.6 , then in the induction step isopropyl $\beta$-D-1-thiogalactopyranoside (IPTG) at $1 \mathrm{mM}$ concentration $\left(25^{\circ} \mathrm{C}\right.$, overnight) was used. Purification of his-tagged Ship2-Sam and EphA2-Sam was achieved by affinity chromatography with an Akta Purifier FPLC System (GE Healthcare, Milano, Italy) and a Nickel column. Finally, proteins were dialyzed in $\mathrm{PBS} \mathrm{pH}=7.4$.

Cell culture and cytotoxicity. Human prostate cancer cell lines (PC-3) were cultured in RPMI 1640 medium supplemented with 10\% fetal bovine serum (FBS) (GIBCO, USA), 2 mM L-glutamine (Lonza, Belgium) in $5 \%$ CO2 humidified atmosphere and harvested at approximately $90 \%$ confluence. The normal human dermal fibroblasts (NHDF) were purchased from Lonza, seeded on T-25 primary flasks (Beckton Dickinson) and maintained in fibroblast basal medium (FBM) supplemented with $2 \% \mathrm{FBS}, 5 \mathrm{mg} / \mathrm{ml} \mathrm{rh}$ insulin, $1 \mathrm{mg} / \mathrm{ml}$ hydrocortisone, $50 \mathrm{mg} / \mathrm{ml}$ ascorbic acid, $5 \mathrm{ng} / \mathrm{ml} \mathrm{rh} \mathrm{FGF} \mathrm{b.} \mathrm{For} \mathrm{cytotoxicity} \mathrm{assay} 4 \times 10^{3}$ and $3.5 \times 10^{3}$ were seeded for cancer and normal cells respectively in $50 \mu \mathrm{l}$ medium per well in 96-well flat-bottom microplates and incubated overnight to allow cell adhesion. Subsequently, culture medium was removed and cells were incubated with $100 \mu \mathrm{l}$ of their growth medium with different concentrations of peptide in quadruplicate for 4 hours. Reduction of cell viability was determined by the crystal violet assay. Shortly, after treatment, culture medium was removed, cells were washed with phosphate-buffered saline (PBS), then they were fixed and stained with $0.1 \%$ (w/v) crystal violet in $25 \%$ methanol for 30 minutes at dark; afterwards, crystal violet was removed and cells were washed twice with double distilled water and let dry. In the end, the cells were solubilized by adding $10 \%(\mathrm{v} / \mathrm{v})$ acetic acid and the amount of dye taken up was quantified with a plate reader (Multiskan Fc 10094, Thermo) at $595 \mathrm{~nm}$. Data were expressed as mean $\pm \mathrm{SD}$ of three independent experiments.

Flow cytometer analysis. PC- 3 cells, plated at a density of $6 \times 10^{5}$, were incubated with FITC-TAT-peptides for 4 hours at $37^{\circ} \mathrm{C}$. Then, the cells were gently washed twice with PBS, permeabilized with $0.1 \%$ Triton X-100 in $33 \mathrm{mM}$ sodium citrate and analyzed with a flow cytometer equipped with a $488 \mathrm{~nm}$ argon laser (FACScan, Becton Dickinson, CA, USA). A total of 20,000 events per sample were collected. Values of fluorescence intensity were obtained from histogram statistic of CellQuest software.

LDH assay. The release of LDH was used as a marker for cytotoxicity. After treatment with $50 \mu \mathrm{M}$ FITC-TAT$(\mathrm{KRI})_{3}$ for 4 hours, cleared supernatants were incubated with reaction buffer for 30 minutes at room temperature according to the manufacturer instructions (ab65393, LDH-Cytotoxicity Assay Kit II). Cells untreated and treated with $1 \%$ Triton-X 100 in PBS were used respectively as negative and positive control. Absorbance was measured at $490 \mathrm{~nm}$ and the cytotoxicity percentage was calculated as: [(Absorbance_test sample - Absorbance_low control)/ (Absorbance_high control - Absorbance_low control) $\times 100$.

Data availability statement. S13-wt NMR structures in presence of TFE have been deposited in the Protein Data Bank (PDB entry code: 5NZ9). NMR structures calculated in presence of TFE for (KRI) ${ }_{3}$, whose amino acid sequence is short and unnatural, are not publicly available but will be provided by the corresponding author on reasonable request.

\section{References}

1. Dyson, J. M., Fedele, C. G., Davies, E. M., Becanovic, J. \& Mitchell, C. A. Phosphoinositide phosphatases: just as important as the kinases. Subcell Biochem 58, 215-279, https://doi.org/10.1007/978-94-007-3012-0_7 (2012).

2. Pirruccello, M. \& De Camilli, P. Inositol 5-phosphatases: insights from the Lowe syndrome protein OCRL. Trends Biochem Sci 37, 134-143, https://doi.org/10.1016/j.tibs.2012.01.002 (2012).

3. Thomas, M. P., Erneux, C. \& Potter, B. V. SHIP2: Structure, Function and Inhibition. Chembiochem 18, 233-247, https://doi. org/10.1002/cbic.201600541 (2017).

4. Suwa, A., Kurama, T. \& Shimokawa, T. SHIP2 and its involvement in various diseases. Expert Opin Ther Targets 14, 727-737, https:// doi.org/10.1517/14728222.2010.492780 (2010). 
5. Lazar, D. F. \& Saltiel, A. R. Lipid phosphatases as drug discovery targets for type 2 diabetes. Nat Rev Drug Discov 5, 333-342, https:// doi.org/10.1038/nrd2007 (2006).

6. Yang, J. et al. High SHIP2 expression indicates poor survival in colorectal cancer. Dis Markers 2014, 218968, https://doi. org/10.1155/2014/218968 (2014).

7. Ye, Y. et al. Suppression of SHIP2 contributes to tumorigenesis and proliferation of gastric cancer cells via activation of Akt. J Gastroenterol 51, 230-240, https://doi.org/10.1007/s00535-015-1101-0 (2016).

8. Prasad, N. K. \& Decker, S. J. SH2-containing 5'-inositol phosphatase, SHIP2, regulates cytoskeleton organization and liganddependent down-regulation of the epidermal growth factor receptor. J Biol Chem 280, 13129-13136, https://doi.org/10.1074/jbc. M410289200 (2005).

9. Zhuang, G., Hunter, S., Hwang, Y. \& Chen, J. Regulation of EphA2 receptor endocytosis by SHIP2 lipid phosphatase via phosphatidylinositol 3-Kinase-dependent Rac1 activation. J Biol Chem 282, 2683-2694, https://doi.org/10.1074/jbc.M608509200 (2007).

10. Ireton, R. C. \& Chen, J. EphA2 receptor tyrosine kinase as a promising target for cancer therapeutics. Curr Cancer Drug Targets 5, 149-157, https://doi.org/10.2174/1568009053765780 (2005).

11. Leone, M., Cellitti, J. \& Pellecchia, M. NMR studies of a heterotypic Sam-Sam domain association: the interaction between the lipid phosphatase Ship2 and the EphA2 receptor. Biochemistry 47, 12721-12728, https://doi.org/10.1021/bi801713f (2008).

12. Lee, H. J. et al. NMR Structure of a Heterodimeric SAM:SAM Complex: Characterization and Manipulation of EphA2 Binding Reveal New Cellular Functions of SHIP2. Structure 20, 41-55, https://doi.org/10.1016/j.str.2011.11.013 (2012).

13. Zhang, L. \& Buck, M. Molecular simulations of a dynamic protein complex: role of salt-bridges and polar interactions in configurational transitions. Biophys J 105, 2412-2417, https://doi.org/10.1016/j.bpj.2013.09.052 (2013).

14. Zhang, L., Borthakur, S. \& Buck, M. Dissociation of a Dynamic Protein Complex Studied by All-Atom Molecular Simulations. Biophys J 110, 877-886, https://doi.org/10.1016/j.bpj.2015.12.036 (2016).

15. Mercurio, F. A. et al. Heterotypic Sam-Sam association between Odin-Sam1 and Arap3-Sam: binding affinity and structural insights. Chembiochem 14, 100-106, https://doi.org/10.1002/cbic.201200592 (2013).

16. Kurabi, A., Brener, S., Mobli, M., Kwan, J. J. \& Donaldson, L. W. A nuclear localization signal at the SAM-SAM domain interface of AIDA-1 suggests a requirement for domain uncoupling prior to nuclear import. J Mol Biol 392, 1168-1177, https://doi.org/10.1016/j. jmb.2009.08.004 (2009)

17. Tantos, A. et al. Structural disorder and local order of hNopp140. Biochim Biophys Acta 1834, 342-350, https://doi.org/10.1016/j. bbapap.2012.08.005 (2013).

18. Sweede, M. et al. Structural and membrane binding properties of the prickle PET domain. Biochemistry 47, 13524-13536, https:// doi.org/10.1021/bi801037h (2008).

19. Mercurio, F. A. et al. CD and NMR conformational studies of a peptide encompassing the Mid Loop interface of Ship2-Sam. Biopolymers 101, 1088-1098, https://doi.org/10.1002/bip.22512 (2014).

20. Mercurio, F. A. et al. Peptide Fragments of Odin-Sam1: Conformational Analysis and Interaction Studies with EphA2-Sam. Chembiochem 16, 1629-1636, https://doi.org/10.1002/cbic.201500197 (2015).

21. Buck, M., Radford, S. E. \& Dobson, C. M. A partially folded state of hen egg white lysozyme in trifluoroethanol: structural characterization and implications for protein folding. Biochemistry 32, 669-678, https://doi.org/10.1021/bi00053a036 (1993).

22. Pimenta, J. et al. NMR solution structure and SRP54M predicted interaction of the N-terminal sequence (1-30) of the ovine Doppel protein. Peptides 49,32-40, https://doi.org/10.1016/j.peptides.2013.08.013 (2013).

23. Mercurio, F. A. et al. Targeting EphA2-Sam and Its Interactome: Design and Evaluation of Helical Peptides Enriched in Charged Residues. Chembiochem 17, 2179-2188, https://doi.org/10.1002/cbic.201600413 (2016).

24. Pellecchia, M. et al. NMR-based techniques in the hit identification and optimisation processes. Expert Opin Ther Targets 8, 597-611, https://doi.org/10.1517/14728222.8.6.597 (2004)

25. Leone, M., Cellitti, J. \& Pellecchia, M. The Sam domain of the lipid phosphatase Ship2 adopts a common model to interact with Arap3-Sam and EphA2-Sam. BMC Struct Biol 9, 59, https://doi.org/10.1186/1472-6807-9-59 (2009).

26. Mercurio, F. A. et al. Solution structure of the first Sam domain of Odin and binding studies with the EphA2 receptor. Biochemistry 51, 2136-2145, https://doi.org/10.1021/bi300141h (2012).

27. Leone, M., Freeze, H. H., Chan, C. S. \& Pellecchia, M. The Nuclear Overhauser Effect in the lead identification process. Curr Drug Discov Technol 3, 91-100 (2006).

28. Yu, J. et al. Limiting angiotensin II signaling with a cell-penetrating peptide mimicking the second intracellular loop of the angiotensin II type-I receptor. Chem Biol Drug Des 76, 70-76, https://doi.org/10.1111/j.1747-0285.2010.00985.x (2010).

29. Scognamiglio, P. L. et al. Destabilisation, aggregation, toxicity and cytosolic mislocalisation of nucleophosmin regions associated with acute myeloid leukemia. Oncotarget 7, 59129-59143, https://doi.org/10.18632/oncotarget.10991 (2016).

30. Miao, H., Burnett, E., Kinch, M., Simon, E. \& Wang, B. Activation of EphA2 kinase suppresses integrin function and causes focaladhesion-kinase dephosphorylation. Nat Cell Biol 2, 62-69, https://doi.org/10.1038/35000008 (2000).

31. Petty, A. et al. A small molecule agonist of EphA2 receptor tyrosine kinase inhibits tumor cell migration in vitro and prostate cancer metastasis in vivo. PLoS One 7, e42120, https://doi.org/10.1371/journal.pone.0042120 (2012).

32. Sharrard, R. M. \& Maitland, N. J. Regulation of protein kinase B activity by PTEN and SHIP2 in human prostate-derived cell lines. Cell Signal 19, 129-138, https://doi.org/10.1016/j.cellsig.2006.05.029 (2007).

33. Chan, F. K., Moriwaki, K. \& De Rosa, M. J. Detection of necrosis by release of lactate dehydrogenase activity. Methods Mol Biol 979, 65-70, https://doi.org/10.1007/978-1-62703-290-2_7 (2013).

34. Kim, J. Y. et al. Necrosis-inducing peptide has the beneficial effect on killing tumor cells through neuropilin (NRP-1) targeting. Oncotarget 7, 32449-32461, https://doi.org/10.18632/oncotarget.8719 (2016).

35. Zamyatnin, A. A., Borchikov, A. S., Vladimirov, M. G. \& Voronina, O. L. The EROP-Moscow oligopeptide database. Nucleic Acids Res 34, D261-266, https://doi.org/10.1093/nar/gkj008 (2006).

36. Harwig, S. S. et al. Gallinacins: cysteine-rich antimicrobial peptides of chicken leukocytes. FEBS Lett 342, 281-285, doi:00145793(94)80517-2 (1994).

37. Zelezetsky, I. et al. Evolution of the primate cathelicidin. Correlation between structural variations and antimicrobial activity. J Biol Chem 281, 19861-19871, https://doi.org/10.1074/jbc.M511108200 (2006).

38. Moore, A. J., Devine, D. A. \& Bibby, M. C. Preliminary experimental anticancer activity of cecropins. Pept Res 7, $265-269$ (1994).

39. Li, X., Li, Y., Han, H., Miller, D. W. \& Wang, G. Solution structures of human LL-37 fragments and NMR-based identification of a minimal membrane-targeting antimicrobial and anticancer region. J Am Chem Soc 128, 5776-5785, https://doi.org/10.1021/ ja0584875 (2006)

40. Huang, W. et al. Learning from host-defense peptides: cationic, amphipathic peptoids with potent anticancer activity. PLoS One 9 , e90397, https://doi.org/10.1371/journal.pone.0090397 (2014).

41. Gross, S., Wilms, D., Krause, J., Brezesinski, G. \& Andra, J. Design of NK-2-derived peptides with improved activity against equine sarcoid cells. J Pept Sci 19, 619-628, https://doi.org/10.1002/psc.2540 (2013).

42. Quinn, B. A. et al. Therapy of pancreatic cancer via an EphA2 receptor-targeted delivery of gemcitabine. Oncotarget 7, 17103-17110, https://doi.org/10.18632/oncotarget.7931 (2016)

43. Wu, B. et al. Design and Characterization of Novel EphA2 Agonists for Targeted Delivery of Chemotherapy to Cancer Cells. Chem Biol 22, 876-887, https://doi.org/10.1016/j.chembiol.2015.06.011 (2015). 
44. Griesinger, C., Otting, G., Wuthrich, K. \& Ernst, R. R. Clean TOCSY for proton spin system identification in macromolecules. J Am Chem Soc 110, 7870-7872, https://doi.org/10.1021/ja00231a044 (1988).

45. Kumar, A., Ernst, R. R. \& Wuthrich, K. A two-dimensional nuclear Overhauser enhancement (2D NOE) experiment for the elucidation of complete proton-proton cross-relaxation networks in biological macromolecules. Biochem Biophys Res Commun 95, 1-6, 0006-291X(80)90695-6 (1980).

46. Piantini, U., Sorensen, O. W. \& Ernst, R. R. Multiple quantum filters for elucidating NMR coupling networks. J Am Chem Soc 104, 6800-6801, https://doi.org/10.1021/ja00388a062 (1982).

47. Hwang, T. L. \& Shaka, A. J. Water suppression that works. Excitation sculpting using arbitrary waveforms and pulsed field gradients. J Magn Reson 112, 275-279 (1995).

48. Wuthrich, K. NMR of Proteins and Nucleic Acids. (Wiley, 1986).

49. Bartels, C., Xia, T., Billeter, M., Güntert, P. \& Wüthrich, K. The program XEASY for computer-supported NMR spectral analysis of biological macromolecules. J. Biomol. NMR 1-10, https://doi.org/10.1007/BF00417486 (1995).

50. Kjaergaard, M., Brander, S. \& Poulsen, F. M. Random coil chemical shift for intrinsically disordered proteins: effects of temperature and pH. J Biomol NMR 49, 139-149, https://doi.org/10.1007/s10858-011-9472-x (2011).

51. Herrmann, T., Guntert, P. \& Wuthrich, K. Protein NMR structure determination with automated NOE assignment using the new software CANDID and the torsion angle dynamics algorithm DYANA. J Mol Biol 319, 209-227, https://doi.org/10.1016/S00222836(02)00241-3 (2002).

52. Koradi, R., Billeter, M. \& Wuthrich, K. MOLMOL: a program for display and analysis of macromolecular structures. J Mol Graph 14(51-55), 29-32 doi:0263785596000094 (1996)

53. Doreleijers, J. F. et al. CING: an integrated residue-based structure validation program suite. J Biomol NMR 54, 267-283, https://doi. org/10.1007/s10858-012-9669-7 (2012)

54. Esposito, V. et al. Exploring the binding of (GGGT) to the HIV-1 integrase: An approach to investigate G-quadruplex aptamer/target protein interactions. Biochimie. https://doi.org/10.1016/j.biochi.2016.04.013 (2016).

55. Farmer, B. T., II et al. Localizing the NADP+ binding site on the MurB enzyme by NMR. Nat Struct Biol 3, 995-997, doi:https://doi. org/10.1038/nsb1296-995 (1996).

\section{Acknowledgements}

The authors are grateful to Leopoldo Zona and Luca De Luca for technical assistance. Financial Support was provided by AIRC (Italian Association for Cancer Research) grant MFAG-15831 (to M.L.).

\section{Author Contributions}

M.L. conceived and coordinated the study; M.L. and F.A.M. designed peptides, performed NMR experiments and analyzed the data; D.M. and C.D.N. conducted CD, SPR studies and analyzed the data; E.M.P. and L.P. prepared protein samples, performed the MST experiment and analyzed the data; R.P. and R.I. carried out cell based assays and analyzed the data. M.L. wrote the manuscript in collaboration with all co-authors. All authors read and approved the manuscript.

\section{Additional Information}

Supplementary information accompanies this paper at https://doi.org/10.1038/s41598-017-17684-5.

Competing Interests: The authors declare that they have no competing interests.

Publisher's note: Springer Nature remains neutral with regard to jurisdictional claims in published maps and institutional affiliations.

(c) (i) Open Access This article is licensed under a Creative Commons Attribution 4.0 International License, which permits use, sharing, adaptation, distribution and reproduction in any medium or format, as long as you give appropriate credit to the original author(s) and the source, provide a link to the Creative Commons license, and indicate if changes were made. The images or other third party material in this article are included in the article's Creative Commons license, unless indicated otherwise in a credit line to the material. If material is not included in the article's Creative Commons license and your intended use is not permitted by statutory regulation or exceeds the permitted use, you will need to obtain permission directly from the copyright holder. To view a copy of this license, visit http://creativecommons.org/licenses/by/4.0/.

(c) The Author(s) 2017 